\title{
Colon and Rectal Surgeon
}

National Cancer Institute

\section{Source}

National Cancer Institute. Colon and Rectal Surgeon. NCI Thesaurus. Code C17860.

A surgeon with advanced training in treating diseases of the colon and rectum. 